Journal de la Société des américanistes

Journal de la Société

des américanistes

\title{
De l'aurore à la nuit : le parcours du roi-soleil maya
}

\section{Claude-François Baudez}

\section{OpenEdition}

Journals

Édition électronique

URL : https://journals.openedition.org/jsa/3095

DOI : 10.4000/jsa.3095

ISSN : 1957-7842

Éditeur

Société des américanistes

Édition imprimée

Date de publication : 1 juin 2006

Pagination : 41-67

ISSN : 0037-9174

\section{Référence électronique}

Claude-François Baudez, « De l'aurore à la nuit : le parcours du roi-soleil maya », Journal de la Société des américanistes [En ligne], 92-1 et 2 | 2006, mis en ligne le 15 janvier 2012, consulté le 03 septembre 2022. URL : http://journals.openedition.org/jsa/3095 ; DOI : https://doi.org/10.4000/jsa.3095 


\title{
DE L'AURORE À LA NUIT : \\ LE PARCOURS DU ROI-SOLEIL MAYA
}

\author{
Claude-François BAUDEZ *
}

\begin{abstract}
Des compositions monumentales, sculptées, modelées ou peintes, provenant de divers sites et produites au cours de la période classique de la civilisation maya, illustrent les principaux moments de la course solaire dans laquelle le souverain est assimilé à l'astre. Ces images mises en séquence comparent la carrière royale au parcours du soleil, de l'aurore à la nuit, et le cycle solaire à la dynastie. La métaphore solaire a légitimé le pouvoir absolu de la royauté maya et la nécessité de la continuité dynastique, tout en démontrant la relation privilégiée qui existe entre le souverain et la (ou sa) terre. [Mots clés : Maya, roi, pouvoir, cycle solaire.]
\end{abstract}

Desde la aurora hasta la noche : el recorrido del rey-sol maya. Imágenes monumentales, esculpidas, modeladas o pintadas, procediendo de varios sitios y creadas durante el periodo clásico de la civilización maya, ilustran los principales momentos del curso solar en el cual el rey es equiparado al astro. Estas imágenes en secuencia comparan la carrera real al recorrido del sol, desde la aurora hasta la noche, y el ciclo solar a la dinastía. La metáfora solar legitimó el poder absoluto de la monarquía maya asi como la necesidad de la continuidad dinástica, mientras demostraba la relación privilegiada que existía entre el soberano y la (o su) tierra. [Palabras claves : maya, rey, poder, ciclo solar.]

From dawn to darkness: the course of the maya king-sun. Carved, modeled or painted monumental images from various sites, created during the Maya Classic period, depict the main moments of the solar course in which the king is likened to the sun. These images in sequence compare the royal career to the course of the sun from dawn to darkness, and the solar cycle to the dynasty. The solar metaphor was used to legitimate the absolute power of the Maya kingship as well as to justify the necessity of dynastic continuity, while demonstrating the special relationship that existed between the king, the earth and his land. [Key words : Maya, king, power, solar cycle.]

Il y a une vingtaine d'années, j’ai suggéré que les Mayas, à l'époque classique, identifiaient leurs rois avec le soleil et comparaient la succession dynastique au

* Archéologue, directeur de recherche honoraire au CNRS [claude.baudez@noos.fr].

Journal de la Société des Américanistes, 2006, 92-1 et 2, pp. 41-67. O Société des Américanistes. 
cycle solaire (Baudez 1988). Cette hypothèse reposait, pour l'essentiel, sur l'analyse d'images de Copán et de Quirigua qui montraient le souverain sortant de la gueule du monstre terrestre et y rentrant, comme le soleil qui se lève et se couche. L'épigraphie ne semblait pas contredire cette proposition, car les titulatures royales font fréquemment allusion au soleil. L'empereur aztèque n'était-il pas lui aussi comparé à cet astre, comme ses lointains cousins mayas ? Si l'hypothèse de la métaphore solaire appliquée à la royauté maya ne fut pas accueillie très favorablement, c'est sans doute parce que les exemples utilisés étaient trop limités ; en effet, ils concernaient seulement la période classique récente (600-900 de notre ère) et la zone sud-est de l'aire maya, et les images dont je disposais ne montraient que des émergences ou des enfouissements, sans étapes intermédiaires.

Aujourd'hui, un corpus élargi montre que la métaphore solaire a été illustrée autant dans les basses terres centrales que dans la zone sud-est, au Classique ancien qu'au Classique récent. Grâce aux découvertes de ces vingt dernières années, la course du roi-soleil peut être reconstituée par des images successives qui en illustrent les plus importants moments. On voit le roi prêt à sortir de terre à Placeres, émerger à Balamkú et à Copán, atteindre le zénith à Kohunlich, descendre à Calakmul, se coucher à Rio Azul et Quirigua, s'enterrer progressivement à Quirigua, Palenque et Copán, enfin, se préparer à renaître à Quirigua et Copán.

Toutes ces images font partie de l'art monumental ofliciel et décorent des architectures ou des sculptures dites « royales », soit parce que des textes ou des motifs les désignent ainsi, soit parce qu'elles apparaissent assez imposantes pour être considérées comme telles. C'est pour cela que le principal sujet anthropomorphe de ces images représente, à nos yeux, le roi de la ville ou de l'État dont provient l'image. Si l'on part du principe que le roi maya s'identifie au soleil, on doit admettre aussi qu'il est le seul du royaume à pouvoir bénéficier de cette métaphore ; l'astre est unique comme l'est le roi régnant.

Certaines images sont relativement simples et leur description, comme leur interprétation, ne requiert pas de longs développements ; d'autres, en revanche, comme la façade de la Structure Margarita de Copán ou la frise de Calakmul, sont d'une grande richesse et complexité et méritent que l'on s'y attarde plus longuement.

La mise en séquence de ces images a pour principal intérêt d'asseoir la métaphore solaire sur des bases plus solides ; en effet, chaque moment du cycle apparaît comme la suite logique du précédent et annonce le suivant. On peut en outre proposer une interprétation plus convaincante d'un motif donné quand on le retrouve sur plusieurs images. Enfin, certains moments de la course du roi-soleil ont été illustrés au Classique ancien et au Classique récent ; en comparant des images d'époques différentes, il est loisible de déterminer continuités et ruptures, de distinguer le nécessaire du contingent et d'évaluer la signification des changements observés. 


\section{L'AURORE}

\section{La frise de Placeres}

Une frise en stuc, pillée dans le site de Placeres, à une cinquantaine de kilomètres au sud-est de Calakmul, fut récupérée et remontée dans la salle maya du Musée national d'anthropologie de Mexico (Figure 1). Par le style et l'iconographie, elle apparaît contemporaine de la frise de Balamkú, datée de la seconde moitié du Classique ancien. Lors de sa découverte (Freidel 2000), elle comprenait au moins deux visages humains, supposés royaux, vus de face, en alternance avec des bacabs, en buste ; il est probable que la frise comportait à l'origine quatre images royales, comme à Balamkú, et quatre bacabs. Le seul visage bien conservé est coiffé d'un heaume d'oiseau et porte sous le menton un masque de jaguar. Les ornements d'oreille carrés sont prolongés, en haut, d'une tête de poisson à dent de requin et, en bas, d'une tête d'oiseau au bec crochu. Le portrait royal est couronné d'un décor complexe de tiges et de volutes, dans lequel on croit reconnaître des épis de maïs. Ce décor ferait allusion à la fertilité terrestre attachée à la personne royale. Le visage et ses ornements sont encadrés, sur trois côtés, de plumes prolongées, dans le bas de la frise, par deux ailes que l'on identifie par la mâchoire stylisée de serpent qui en constitue l'armature. Le roi est donc ici un oiseau, symbole du soleil diurne, par son heaume, ses ailes et ses plumes. Cet oiseau ne vole pas et se trouve encore dans le monde souterrain, au même niveau que les bacabs qui l'entourent. Ces créatures mythiques, associées à la terre féconde, présentent dans leurs mains ouvertes des expressions symboliques ornées de nœuds, de volutes et de guirlandes. Le bacab de droite tient dans une main une tête de lapin. Celui de gauche expose l'association $\mathrm{mol}$-croix $\mathrm{kan}$, précédée d'un chiffre à moitié effacé. Sur la Stèle 2 de Machaquila $(800 \mathrm{AD})$, un bacab offre au roi la même expression précédée du chiffre 7 (Graham 1967, figure 44). D'autres signes et symboles sont dispersés autour des bacabs, en particulier ceux qui ressemblent à des « rouages » et qui évoquent la feuille dentelée du nénuphar.

Le souverain, représenté comme un oiseau, s'identifie au soleil diurne ; bien qu'il soit encore en terre, son lever est imminent. Le décor de façade de Placeres met l'accent sur l'origine terrestre du roi et son rôle de garant de la fertilité. En outre le souverain y apparaît comme le soleil prêt à s'élancer pour régner sur la terre et éclairer le monde.

\section{LE LEVER DU JOUR (OU LE SOLEIL ASCENDANT)}

\section{La frise de Balamkú}

Le début de la carrière royale est illustré sur la façade d'un temple (Structure 1) de Balamkú (Campeche), daté de la seconde moitié du Classique ancien 


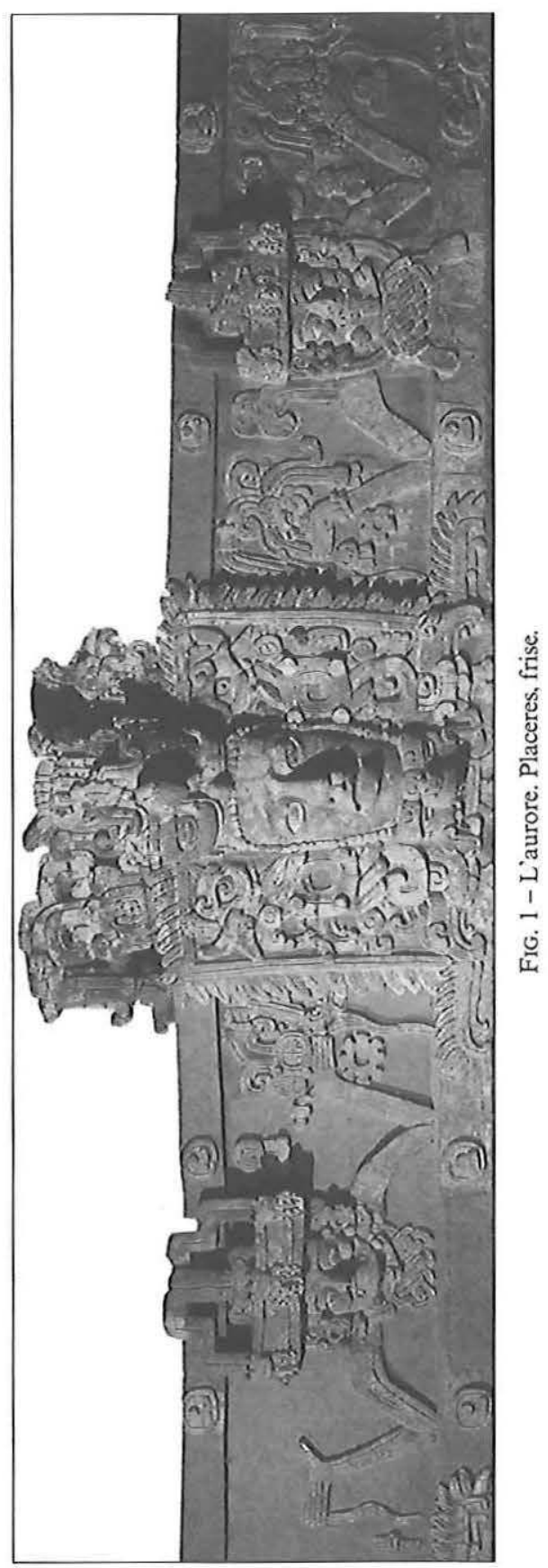




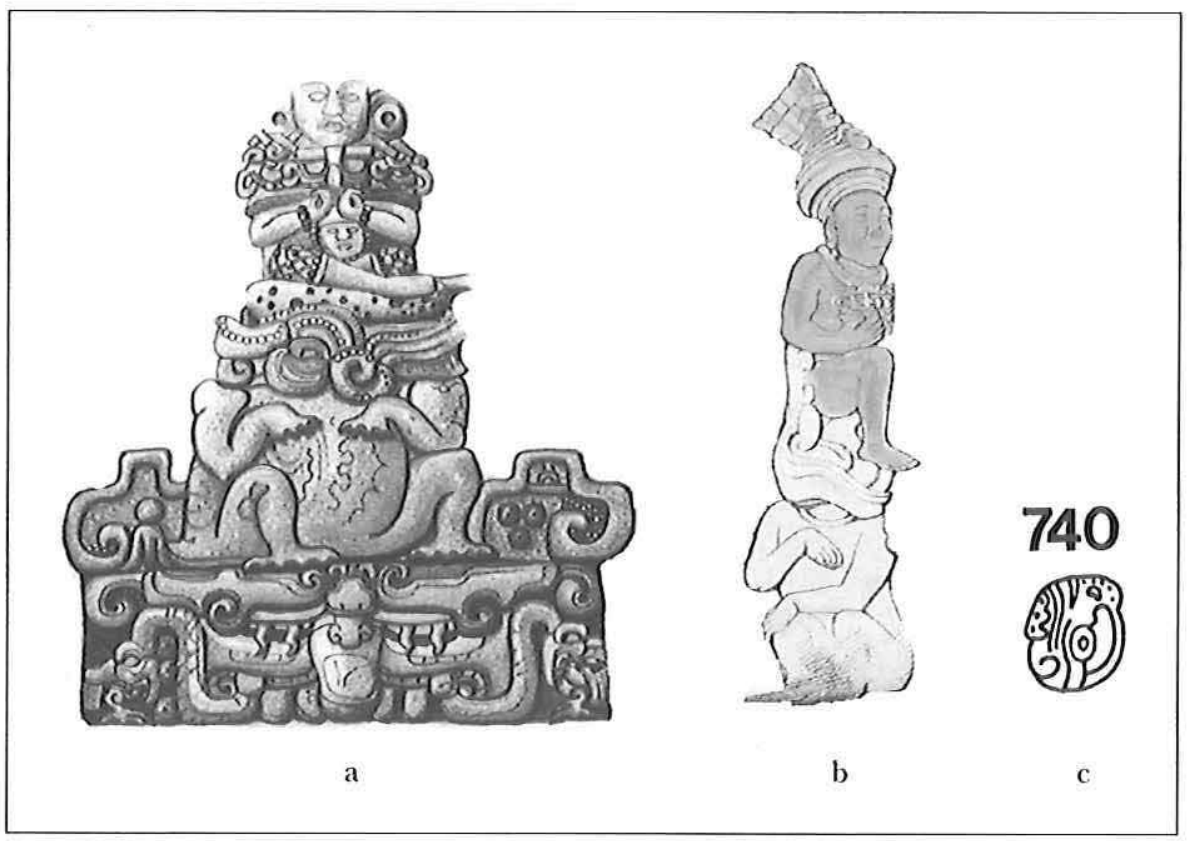

FIg. 2 - Le lever du jour
a. Balamkú, frise, détail (d'après un dessin d'A. Dowd),
b. Copán, Stèle N, détail,
c. glyphe T740.

(400-600 de notre ère. Baudez 1996a). Sur cette frise modelée en stuc et peinte, longue de $17 \mathrm{~m}$, sont figurées quatre - par respect pour les directions cardinales scènes d'émergence où le souverain sort de terre comme le soleil à son lever. Chaque composition montre un crapaud ou un crocodile, la tête renversée et la gueule béante, qui vomit le roi ; celui-ci apparaît de face et assis sur un coussin (Figure 2a). L'animal est installé lui-même dans la fente, prolongée sur les côtés par deux volutes, d'un masque du monstre terrestre cauac. Des jaguars assis ou agenouillés, entravés comme des victimes de sacrifice, alternent avec les scènes d'émergence (Baudez 1996a). Les deux modalités contraires du monde souterrain sont ainsi montrées en alternance : l'aspect humide, fertile, que le monstre cauac représente ; l'aspect aride de l'inframonde conçu comme domaine des morts, des sacrifices sanglants et du soleil nocturne, que le jaguar incarne. L'attitude majestueuse du roi indique qu'il sort de terre, vivant, et non qu'il s'y enfonce à l'état de cadavre. Si cela était le cas, ses membres seraient disloqués comme ceux de pantins, à l'image des victimes sacrifiées (longtemps appelées « Danzantes ») de la première période de Monte Albán (Marcus et Flannery 1996, figure 173). 
L'originalité des scènes d'émergence de Balamkú tient à l'image dédoublée de la terre, à la fois monstre cauac et animal amphibie. La forme habituelle consiste en un monstre anthropomorphe à tête de crocodile qui vomit le roi, comme sur la Stèle $\mathrm{N}$ de Copán (761 de notre ère ; Figure 2b). La tête renversée du crapaud, comme celle du crocodile, son doublet, est analogue au glyphe T740, une tête de crapaud orientée vers le haut, qui signifie "naître » (Figure 2c). Aussi l'émergence hors de terre du souverain peut être une référence non tant à son accession au trône qu'à sa naissance. Animaux et cauac établissent cette fois encore que la terre dont émerge le souverain est la terre dans son aspect humide et fécond, ce que confirment les nénuphars qui décoraient le haut de la frise. Cette dernière ne se contente pas d'identifier le souverain au soleil levant ; elle proclame également son origine terrestre dont le roi tire légitimité et pouvoir. Contrairement à l'empereur de Chine, le roi maya n'est pas fils du ciel mais fils de la terre. La naissance est immédiatement suivie de l'accession au trône qu'indique la position assise du roi ; une des expressions glyphiques de l'accession, chumlah ta-Ahaw-le, est en effet traduite par « il fut assis comme ahau ».

\section{La façade de la structure Margarita de Copán}

Le décor en stuc modelé et peint de la façade ouest de la Structure Margarita (16-sub) de Copán, construite au $v^{\mathrm{e}}$ siècle par le Souverain $\mathrm{n}^{\circ} 2$, fils du fondateur de la dynastie, célèbre l'accession de son père (Figure 3a). Le motif central consiste en deux oiseaux vus de profil, aux cous enlacés. L'armature des deux ailes visibles est, selon l'usage, une tête stylisée de serpent. Les serres affrontées (qui indiquent deux oiseaux distincts et non un oiseau bicéphale) sont placées juste au-dessus de 9 imix. À la droite de cette expression glyphique, on reconnaît deux traces de pas dirigées vers le haut. Cet ensemble est compris dans un cadre cosmique. Au bas de la composition une frise horizontale représente la terre. Les trois autres côtés du cadre sont constitués de deux frises concentriques qui représentent le ciel : la frise interne figure les mâchoires du monstre céleste ; l'externe montre le même monstre en entier sous sa forme bicéphale.

\section{La terre}

Le bas du décor est isolé du reste de la composition par une double ligne et contient plusieurs signes en cartouche. Au centre est un glyphe ou un emblème en cartouche semi-circulaire dans lequel on croit reconnaitre le motif de la natte, symbole de pouvoir. Aux deux extrémités, on trouve le signe T522, des bandes diagonales croisées en cartouche circulaire, couronné par l'affixe T124. Entre le motif central et T522, deux cartouches semi-circulaires contiennent T528, cauac. Les cartouches du signe principal et des glyphes cauac se détachent sur un cercle denté, image de la feuille dentelée du nénuphar. T528 exprime ici la terre dans son aspect humide et fertile (Baudez 2002, pp. 167 sq). Le signe des bandes diagonales 


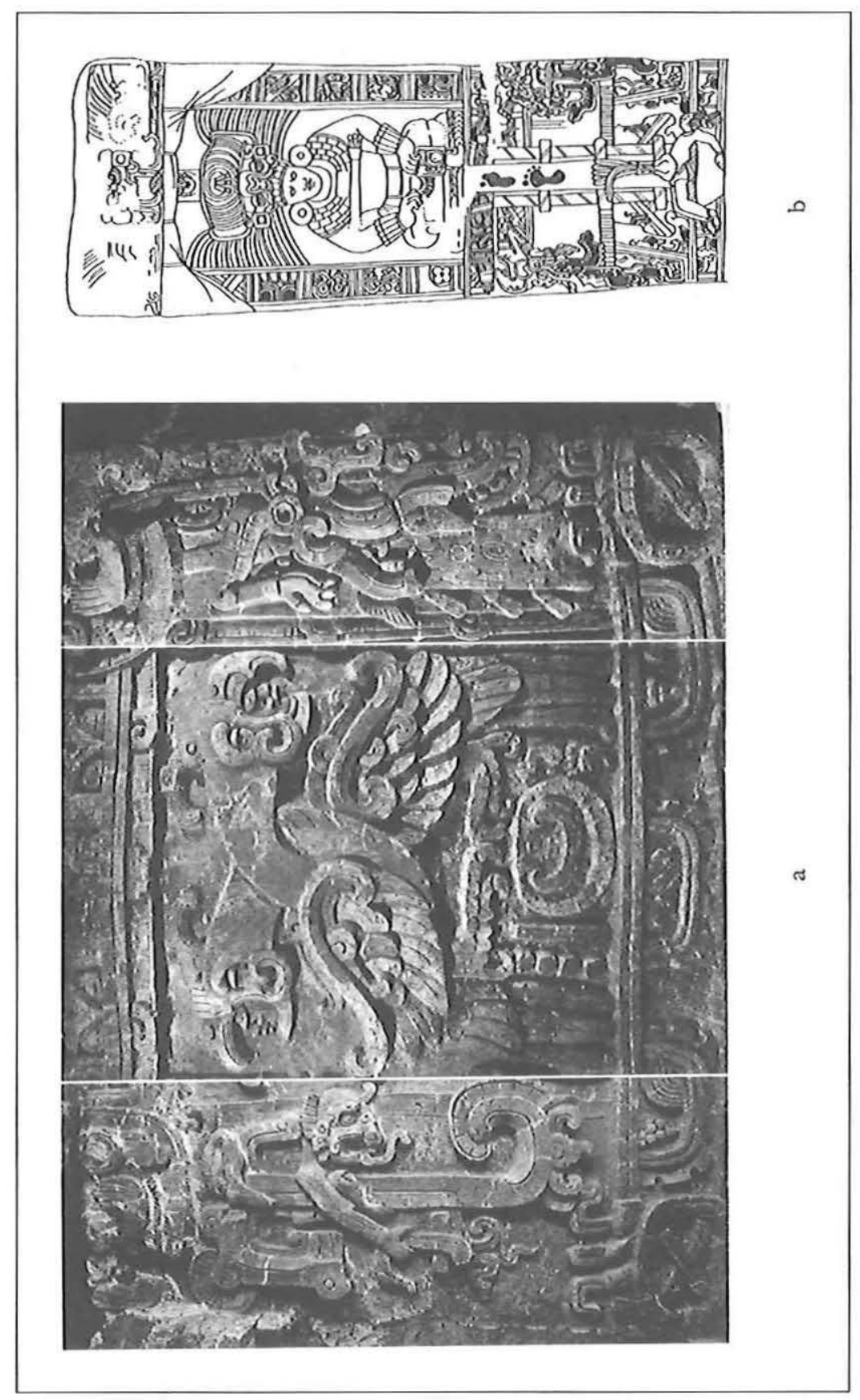

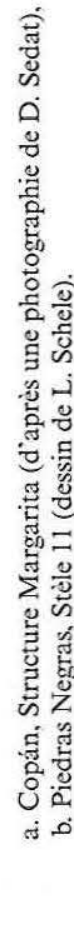


croisées, surmontées de l'affixe T124 en trois parties, est un des éléments de l'emblème tripartite qui comprend, en outre, une dent de requin (remplacée au Classique récent par un aiguillon de raie) et une coquille ${ }^{1}$. La dent de requin, comme plus tard l'aiguillon de raie, est pour les Mayas l'instrument exemplaire d'autosacrifice. La coquille, conçue comme l'équivalent d'un squelette, signifie la mort. Les bandes croisées ont une signification voisine, comme le montrent divers cas de substitution par T509, cimi, mort ${ }^{2}$. Associé au signe $k i n$, l'ensemble de ces trois symboles de mort et de sacrifice qualifie le soleil nocturne. Bien que T124: 522 soit, sur la façade de Margarita, détaché du contexte de l'emblème tripartite, il n'y a pas de raison de penser qu'il puisse avoir un sens différent. Sans préjuger de l'interprétation du signe central, on peut voir, dans la juxtaposition de cauac et des bandes croisées, la manifestation de l'opposition des deux aspects de l'inframonde : vie/mort ou fertilité/aridité, illustrée à Balamkú par l'opposition monstre cauac/jaguar.

\section{Le ciel}

Le ciel est présenté comme un double cadre en U inversé. Le cadre interne pourrait représenter trois côtés d'une gueule qui contiendrait le motif central ; chaque côté possède au centre un élément trilobé flanqué de deux volutes, figurant des incisives en $T$ et deux crocs en crochet. Nous retrouvons cette combinaison dans l'iconographie d'Izapa ${ }^{3}$ (Figure 4c) et sur la frise de la Structure 2-sub de Calakmul (voir plus loin la Figure 7).

Le cadre externe (Figure 3a) désigne le monstre bicéphale céleste. Le corps du monstre est une frise où se répète, au moins une fois, T510, le glyphe de l'étoile, qui encadre un autre signe provisoirement non identifié. Un médaillon circulaire assez endommagé, dans lequel on distingue divers signes dont une main ouverte, forme l'articulation entre la bande céleste et chaque tête du monstre. À droite, sa tête " vivante ", une patte et une partie de son buste sont disposées verticalement. On notera la barbe, la dent de requin et le prolongement du museau par ce qui pourrait être une feuille de nénuphar. La colonne qui poursuit la gueule vers le bas représente le flot d'eau bienfaisante que le ciel déverse sur la terre. La tête décharnée du monstre se trouve du côté gauche : la mâchoire supérieure est une simple bande au bout retroussé, et la mandibule est clairement décharnée. L'œil est indiqué par deux angles droits concentriques. Un singe à tête squelettique qui a conservé sa crête sagittale s'accroche à la mâchoire supérieure ; sa queue vient toucher l'occiput. Il tient dans la main droite une hache fumante. Le singe prend parfois la place de kin dans les glyphes à figure entière à Yaxchilan (Linteau 48 : Graham 1979) et à Copán (Stèle D : Baudez 1994, figure 11). Ici, décharné, il représente le soleil mort (c'est-à-dire nocturne); la hache fumante qu'il tient pourrait être l'équivalent de la torche tenue par un ara dans le codex de Dresde (p. 40b) et qui renvoie à la sécheresse, à la foudre et aux incendies qu'elle provoque. Les deux têtes du monstre céleste expriment les deux pôles de l'oppo- 


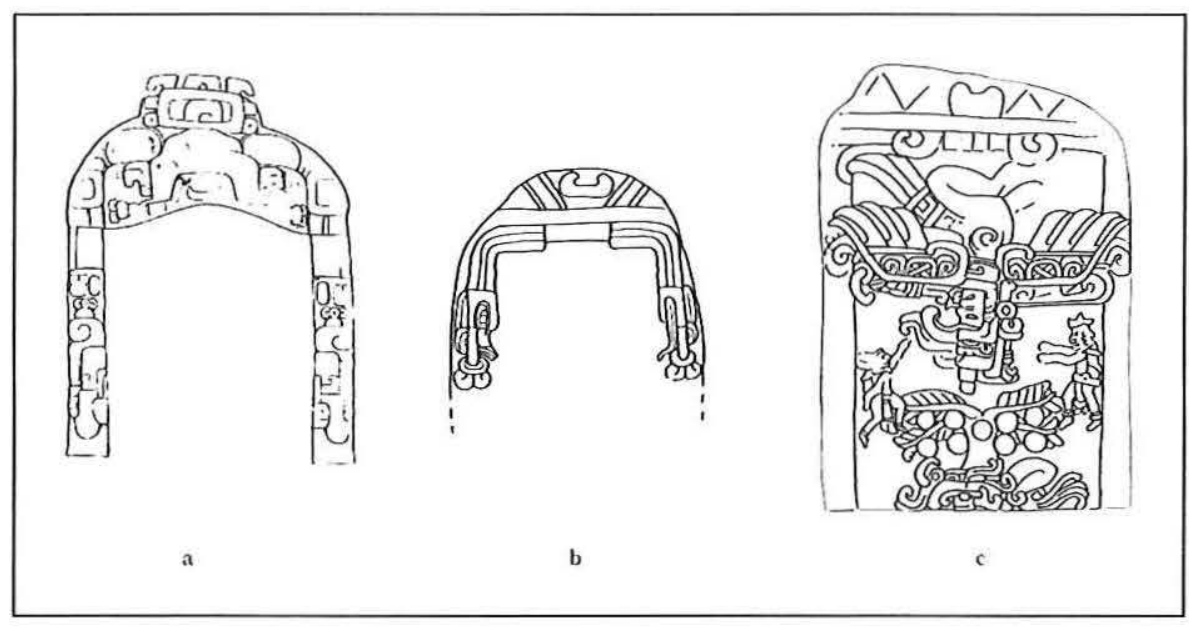

FIG. 4 - a. Tres Zapotes, Stèle D, encadrement,

b. Izapa, Stèle 23 , encadrement,

c. Izapa, Stèle 2 (dessin de G. Norman).

sition: saison des pluies/saison sèche, humidité/sécheresse, fertilité/aridité, vie/mort, ce que l'alternance des signes cauac et des bandes croisées exprime également dans la bande terrestre.

\section{Le motif principal}

Les deux oiseaux, aux cous enlacés, sont à gauche un quetzal ( $\left.k^{\prime} u k^{\prime}\right)$, à droite un ara $\left(m o^{\prime}\right)$, volatiles aux couleurs vives qui, dans l'iconographie maya classique, symbolisent tous deux le soleil diurne. L'un et l'autre ont sur la tête le préfixe T16, yax, traduit dans ce contexte par "nouveau ». Les têtes humaines dans leur bec sont très semblables; celle de droite, dans le bec de l'ara, se distingue cependant de celle de gauche par une lèvre supérieure saillante, d'où dépasse une dent de requin ou des dents taillées en T. Une ride profonde entoure sa bouche, faisant paraître son visage plus âgé. Les deux personnages pourraient être des formes ancestrales des « dieux pagayeurs » du Classique récent, bien que fassent ici défaut les éléments qui, à cette dernière période, distinguent ces êtres surnaturels. Au motif iconographique des deux oiseaux confondus correspond T744b, un glyphe hybride de quetzal et d'ara qui combine la crête du premier avec le bec crochu et la peau granuleuse autour de l'œil du second (Figure 5b). Dans les inscriptions de Copán, ce glyphe précédé de l'expression $k$ 'inich désigne le souverain fondateur de la dynastie de cette cité, sur laquelle les rois ont régné $\mathrm{du}^{\mathrm{e}} \mathrm{vau}^{\mathrm{a}}$ $\mathrm{IX}^{\mathrm{c}}$ siècle. Les épigraphistes déchiffrent littéralement ce nom ou ce titre en $Y a x$ $K^{\prime} u k^{\prime} M o^{\prime}$, soit « Nouveau Quetzal Ara ». Il n'est pas sûr que les Mayas aient 


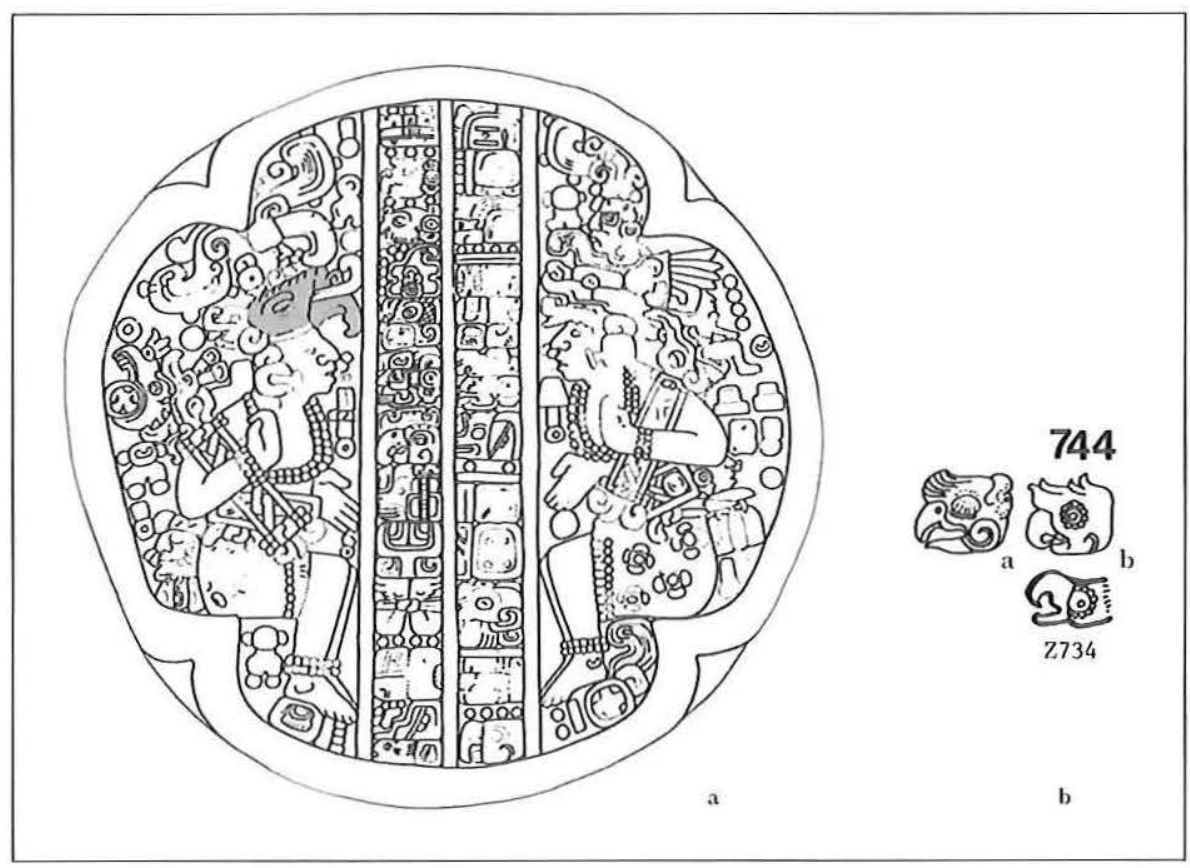

FIG. 5 - a. Copán, disque Motmot (dessin de B. Fash),

b. T744a = k'uk', quetzal ; T744b = k'uk'-mo', quetzal-ara ; Z734 = $m o^{\prime}$, ara

ainsi appelé leur roi ; en effet, leurs noms et leurs titres font appel à des symboles qui constituent une sorte d'héraldique et renvoient le plus souvent au soleil, auquel les rois mayas s'identifiaient. Notons, en outre, que comme Yax préfixe la tête de nos deux oiseaux, l'ensemble devrait être plutôt " lu » Yax K'uk' Yax Mo'.

Le quetzal désigne couramment le soleil diurne dans l'iconographie maya ; on le trouve notamment au sommet de cosmogrammes à Palenque (panneaux de la Croix et de la Croix Feuillue, couvercle du sarcophage du temple des Inscriptions ; Greene Robertson 1983, 1991), Piedras Negras (Stèles 6 et 11 : Figure 3b), ou Copán (sur le dos de la Stèle H. Maudslay 1889-1902, I, plate 61). Sur le côté est de la Stèle $\mathrm{C}$ de ce dernier site, le jeune roi 18 Lapin, représenté en train de sortir de terre, porte à la ceinture un masque de quetzal posé directement sur un masque cauac, image de la prise de pouvoir du roi (soleil) sur la terre (Baudez 1994, figure 7b). Sur les rampes de l'escalier hiéroglyphique de la Structure 26, le même motif est indéfiniment répété : un quetzal traité en style Teotihuacan (c'est-à-dire aux yeux cerclés et au bec très élargi vu de face) domine un monstre cauac, image du roi-soleil dominant le monde (Fash 1991, figure 10). 
L'ara est une autre icône du soleil diurne et on le trouve à Copán dans des contextes comparables à ceux dans lesquels figure le quetzal. Au sommet de la face ouest de la Stèle B, deux têtes d'ara (que les anciens voyageurs prenaient pour des têtes d'éléphant) reposent sur la tête du monstre cauac, de la gueule duquel émerge 18 Lapin (Baudez 1994, figure 5a). Trois têtes d'ara à tenon et des fragments de serres proviennent du temple de la Structure 26 et de son escalier hiéroglyphique : cet oiseau occupait la place supérieure du cosmogramme que constitue cette structure. Deux têtes d'ara sont les marqueurs latéraux d'au moins deux terrains successifs du jeu de balle A. Ces mêmes volatiles, entiers, décorent les structures latérales du terrain A-III (Fash 1991, plate III). Au Postclassique, l'ara était encore l'image du soleil diurne, comme l'indique le nom de l'astre vénéré à Izamal, $K^{\prime}$ 'inich $k^{\prime} a k^{\prime} m o^{\prime}$, soit « face du soleil ara de feu » (Lizana 1893). Dans la mesure où quetzal et ara symbolisent tous deux le soleil diurne, on pourrait penser que l'on a à faire à des doublets, procédé stylistique d'usage courant en Mésoamérique où des termes voisins sont répétés ensemble. C'est le cas, dans l'iconographie classique, du crapaud et du crocodile qui, renvoyant au milieu aquatique des bajos, forment souvent une paire sans que l'on puisse distinguer leurs rôles respectifs. Les deux oiseaux cependant sont différents car tant l'image que le glyphe indiquent la fusion de deux créatures distinctes. La différence entre les deux volatiles tient, en réalité, à leur environnement : le quetzal est un oiseau des hautes terres, l'ara des basses terres. Je suggère que les oiseaux fusionnés de Margarita, tout comme le glyphe T744b, forment le nom, le titre ou le blason adopté par le souverain fondateur pour proclamer la réunion des deux zones, peut-être sous son autorité. Ce serait l'équivalent de la coiffure pharaonique qui combinait les symboles de la Haute et de la Basse Égypte. Dans cette hypothèse, le choix d'un tel nom serait un acte politique.

Sur un crâne de pécari de la Tombe 1 de Copán, un des prédécesseurs du fondateur, quelque cinquante ans plus tôt, est coiffé d'une tête d'ara (Stuart 2004). Un des vases de la tombe (Chambre 2) de Margarita a pour motif, trois fois répété, un temple de style Teotihuacan dans lequel se trouve un homme au masque de quetzal, traité dans le même style (Reents-Budet et al. 2004). Sur le disque associé à la Structure Motmot (l'une des structures 26-sub) qui représente le fondateur en compagnie de son fils, la coiffure du premier combine la tête du quetzal au bec crochu de l'ara (Figure 5a. Stuart 2004, chapitre 11, figure 11). Sur l'Autel Q, monument dynastique inauguré par le roi Soleil Levant le 29 décembre 775 , le fondateur porte une cape de plumes ; un oiseau hybride qui possède les longues plumes de queue du quetzal, l'œil et le bec de l'ara est posé sur son turban. L'inscription sculptée sur le dessus du monument cite par trois fois le fondateur. D'après David Stuart (2004), elle raconte que, le 9 septembre 426, il est venu de la " Maison des Origines » où, trois jours plus tôt, il avait reçu un emblème de commandement (kawil). Cinq mois plus tard, il arrive à Copán et prend peu après - suppose-t-on - le pouvoir. En vertu des nombreuses images et objets 
originaires du Mexique central qui font leur apparition à Copán à cette époque, certains chercheurs sont tentés de considérer Teotihuacan comme une possible "Maison des Origines ». Cette interprétation serait parfaitement en accord avec notre hypothèse du roi incluant les hautes terres dans son blason. Cependant les analyses, effectuées sur ses restes osseux, des taux d'isotopes stables de strontium et d'oxygène indiquent que, si le roi n'est pas originaire de Copán, il n'a pas pour autant passé sa jeunesse dans la vallée de Mexico (Buikstra et al. 2004).

Sur la façade de Margarita, les serres des oiseaux reposent sur l'expression 9 imix. Imix (T501) est le nom du premier jour du tzolkin ou calendrier cérémoniel de 260 jours. Bien qu'il soit ici précédé d'un chiffre, il ne forme pas une date car la position calendaire dans le haab, le calendrier de 365 jours, fait défaut. Dans le calendrier aztèque, imix correspond à cipactli, la terre sous forme d'un crocodile. Le dessin de T501, comme l'a montré Thompson (1971), est une fleur stylisée de nénuphar et, de ce fait, figure souvent comme symbole de la terre humide qui est, par extension, fertile et féconde. Le chiffre 9, bolon, peut signifier « nombreux» ou " innombrable» (Thompson 1970, p. 227) et, comme tel, accompagne des composés glyphiques dont la valeur est symbolique et non calendaire.

Au Classique ancien, les doublets 9 imix/7 kan apparaissent comme les équivalents des expressions - courantes au Classique récent - appelées par Kubler (1977) 7-tête et 9-tête. Ces expressions, qui peuvent apparaître isolément ou former une paire, ont pour signe principal une tête ophidienne à la mâchoire inférieure décharnée ou absente, tête accompagnée de certains affixes et précédée du chiffre 7 ou 9. Dans tous les cas, ces expressions se réfèrent à la terre humide et fertile. Au même titre que les autres figurations de la terre (monstre cauac, crocodile ou crapaud, médaillon cruciforme ou forme en T), elles servent de siège ou de piédestal au souverain qui, par là, exprime son pouvoir sur la terre (Baudez 1994). Il s'agit à la fois de la terre organique, de la Terre Mère, et de sa terre, c'est-à-dire de son territoire. Sur le disque Motmot, les pieds du fondateur reposent sur 9 imix (comme sur la façade de Margarita) et ceux du Souverain 2 sur 7 kan (Figure 5a). L'image des deux oiseaux en un (qu'elle soit emblème, titre ou nom du fondateur), dont les serres reposent directement sur 9 imix, exprime la prise de pouvoir du roi. Le souverain, issu du monde souterrain, est monté sur son trône terrestre, comme l'indiquent les traces de ses pas. La façade de Margarita proclame la prise de pouvoir du fondateur qui s'exprime par l'installation sur la surface terrestre (9 imix) de son emblème (ou de son nom) fait de deux oiseaux fusionnés. La combinaison des symboles du soleil des hautes terres et du soleil des basses terres traduit la volonté du fondateur de réunir ces deux zones probablement sous son autorité. Il est également possible que la fusion des deux oiseaux fasse allusion à Copán qui occupe une situation géographique intermédiaire entre basses et hautes terres. L'origine souterraine du roi, qu'indiquent les traces 
de ses pas, identifie le souverain au soleil, mais aussi aux plantes cultivées, au maïs en particulier.

\section{La Stèle 11 de Piedras Negras}

Les Stèles 6 et 11 de Piedras Negras, datées respectivement de 687 et 731 de notre ère, soit près de trois siècles après la façade de la Structure Margarita, sont structurellement analogues à cette dernière et illustrent le même thème de l'accession conçue comme une émergence (Figure 3b). Le roi est assis dans une niche, qui le place au-dessus de ses sujets, et à laquelle ses pas l'ont conduit, comme le montrent leurs traces. Le bas de l'échelle qui lui a permis d'y accéder repose sur une bande terrestre divisée en panneaux contenant T526, caban, terre. La niche est encadrée par une frise constituée de divers symboles célestes - et pas seulement celui de l'étoile - qui tient lieu de corps à un monstre bicéphale dont les têtes contrastées encadrent l'échelle. Ici cependant, comme souvent au Classique récent, la tête arrière et squelettique du monstre est inversée et coiffée du signe kin et de l'emblème tripartite. L'équivalent du 9 imix de Margarita serait, sur les stèles de Piedras Negras, le motif que Schele et Miller (1986, p. 112) interprètent comme une effigie de crocodile, faite de roseaux, au-dessus de laquelle le souverain est assis.

Les stèles à niche de Piedras Negras combinent les deux façons utilisées par les Mayas pour représenter l'accession. La position élevée du souverain montre l'accession comme une émergence hors de terre, suivie d'une ascension. La niche devant laquelle le roi est assis figure la gueule du monstre terrestre, comme sur l'Autel 4 de La Venta ou le Monument 22 de Quirigua.

\section{MIDI}

\section{Les masques de Kohumlich}

L'escalier qui gravit la Structure A-1 de Kohunlich (Quintana Roo) est encadré à chaque degré de la pyramide par deux masques en stuc peint (Figure 6). Le visage du soleil en fort relief, qui représente le souverain, est le motif central : sous d'épais sourcils, ses yeux sont recouverts du glyphe $k i n$, sa bouche est arquée (héritage olmèque) et flanquée de deux crochets (émanations ?). Le masque de coiffure est ici détruit ; le masque de menton, au museau aplati, est celui du jaguar. Les ornements d'oreille en quinconce sont encadrés de bandes nouées et de deux masques de profil : ceux du haut représentent un poisson ${ }^{4}$ et ceux du bas des oiseaux à bec crochu. Le visage du roi avec ses ornements est encadré par deux profils de serpent très stylisés, dirigés vers le bas. L'image royale est présentée dans la gueule du monstre céleste, un équivalent des mâchoires stylisées (avec incisives 


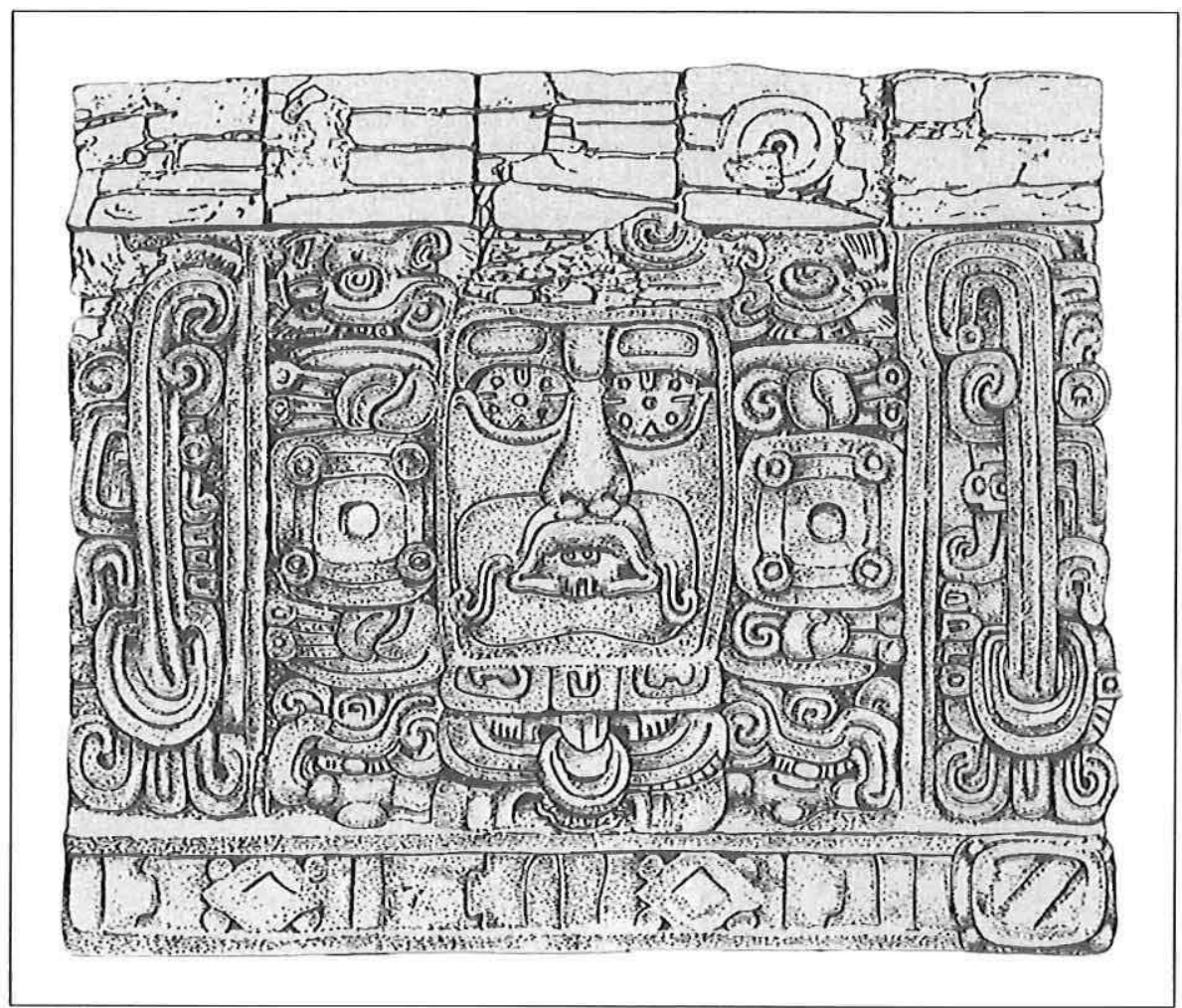

FIG. 6 - Midi

Kohunlich, Structure A-1, masque du troisième degré, à droite de l'escalier (dessin de César Fernández).

en T et crocs) qui, sur la façade de Margarita, contiennent le nom du roi sur trois côtés. On trouve déjà cette composition sur la Stèle D de Tres Zapotes (Figure 4a) ou sur la Stèle 23 d'Izapa, où un masque frontal au sommet et deux profils sur les côtés (Figure $4 \mathrm{~b}$ ) forment la gueule du monstre qui contient une scène à plusieurs personnages.

Une frise céleste, dans laquelle on reconnaît T510, le glyphe étoile (lamat) répété, court sous l'ensemble. Une bande oblique en cartouche se trouve à l'extrémité de la frise. Ici le roi-soleil n'a plus de contact avec la terre, comme sur la façade de Margarita. Son efligie est placée au-dessus d'une frise céleste ; il se trouve donc entièrement au ciel, sinon au zénith. Cette situation est interprétée comme celle de l'apogée du règne. 


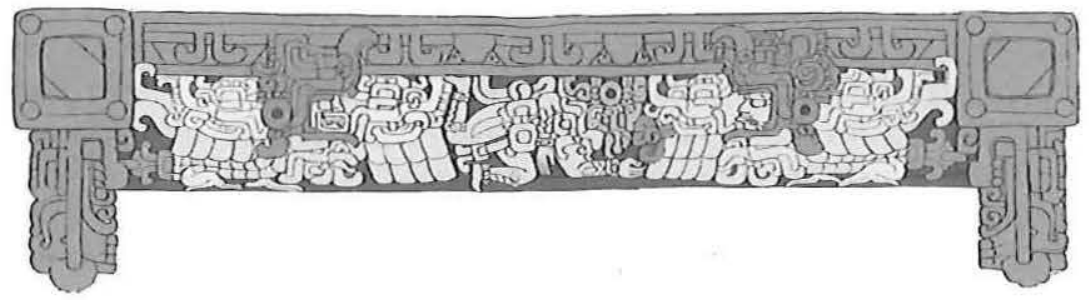

FIG. 7 - L'après-midi

Calakmul, Structure 2-sub (dessin de R. Ruiz Rodarte, courtoisie Proyecto Arqueológico Calakmul).

\section{L'APRÈS-MIDI (OU LE SOLEIL DESCENDANT)}

\section{Frise de la Structure 2-sub de Calakmul}

La Structure 2-Sub de Calakmul comprend une porte monumentale qui donne accès à une cour bordée d'édifices. La frise modelée en stuc-longue de plus de $20 \mathrm{~m}$ - qui la décore (Figure 7) est datée par Ramón Carrasco, son découvreur, du Préclassique récent. Une scène à trois personnages, un homme masqué entre deux oiseaux qui se font face, est surmontée d'une frise prolongée aux extrémités par deux têtes de serpent dirigées vers le bas. La frise voit la répétition à l'infini d'un élément en T flanqué de deux crochets, motif emblématique de la gueule du monstre céleste, comme sur le cadre interne de la frise céleste sur la façade de Margarita (Figure 3) ou sur certaines stèles d'Izapa (Figure 4c). Aux extrémités de la frise se trouvent deux médaillons carrés contenant une bande oblique comme aux bouts de la frise céleste de Kohunlich (Figure 6). Alors que là le masque solaire se trouvait au-dessus de la frise céleste, ici le personnage principal est placé au-dessous du ciel, et en tombe. Non seulement il tourne le dos à la frise, mais ses membres pliés en diverses directions révèlent le désordre d'une chute dans le vide. Son visage est recouvert d'un masque, comme les souverains morts et sur le point d'être enterrés des Monuments 23 et 24 de Quirigua (voir plus loin la Figure 9) ; ici cependant, le masque est reptilien et non félin. La nature solaire du personnage est révélée par les cheveux noués en boucle qui dépassent du masque ; cette coiffure est caractéristique des captifs et du soleil en tant que patron du sacrifice. Les deux oiseaux qui encadrent le personnage ne tombent pas comme lui. Ils sont entiers avec ailes (dont l'armature est une tête de serpent), pattes et queue. Ils sont aussi affublés d'un important masque de « menton ». Les visages humains visibles dans leurs becs sont légèrement différents. La signification des deux oiseaux et leur rôle dans la composition ne sont pas clairs et 
pourront être compris seulement quand on disposera d'autres exemples comparables. Les oiseaux affrontés rappellent ceux qui sont sculptés sur les Autels 9 et 10 de Kaminaljuyú (Parsons 1986, figures 140, 141), des cylindres tétrapodes provenant d'un même dépôt. L'oiseau de l'Autel 9 regarde vers la droite, celui de l'Autel 10 dans la direction opposée. Leurs ailes sont marquées l'une du signe kin, l'autre du signe $a k b a l$, et leurs pattes se terminent en gueule de serpent. Comme sur la frise de Calakmul, les oiseaux de Kaminaljuyú sont limités par une tête verticale de serpent et portent pectoral et ornement d'oreille. Il est probable que ces autels cylindriques furent utilisés ensemble pour encadrer un personnage central, peut-être la figure anthropomorphe trouvée dans le même dépôt. Sur des vases du Classique ancien, on trouve parfois des oiseaux semblables aux ailes déployées avec kin sur une aile et $a k b a l$ sur l'autre (Hellmuth 1987, figure 491).

Le personnage central de la frise de Calakmul représente le souverain mort, identifié au soleil couchant. Sa chute est le premier moment d'une descente vers la terre, avant de s'enfoncer dans l'inframonde. La Stèle 2 d'Izapa (Figure 4c) peut exprimer la même chose car on y voit un homme-oiseau tombant la tête la première vers une frondaison grande ouverte, issue d'une tête de monstre terrestre. Même si l'on a à faire au même thème, l'iconographie est fort différente de celle des images mayas. Sur celles-ci, en effet, le roi qui tombe n'est pas un oiseau et la terre qui s'apprête à le recevoir n'est pas un arbre ouvert.

\section{LE JOUR TOMBE}

\section{Peinture murale de la Tombe 1 de Rio Azul}

Peinte sur le mur du fond de la tombe, une série initiale (donnant la date correspondant à 417 de notre ère) sépare deux images (Figure 8). Sur celle de droite, une tête de jaguar solaire marquée de deux glyphes kin est placée juste au-dessus de la large fente qui entame le front d'un monstre terrestre cauac, de profil droit. L'œil du monstre est couvert par des bandes croisées, le museau retroussé s'inscrit sur une feuille de nénuphar, et la mâchoire supérieure est garnie de trois dents pointues de crocodile et d'une dent de requin. La mandibule s'orne d'une barbe. L'ornement d'oreille en trois parties est prolongé sur la gauche par un museau recourbé sur lequel on distingue un nez et ses tubes.

Sur l'autre image, le monstre terrestre, de profil gauche, est traité différemment. Sa nature terrestre est confirmée par le médaillon quadrilobé qu'il porte sur le front. Une tête grotesque et un animal de profil dessiné schématiquement sont placés au-dessus. Trois flammes recouvrent l'œil du monstre. Des signes cauac ornent ses dents ainsi que l'élément supérieur de l'ornement d'oreille. Le monstre est ici dépourvu de mandibule ; sous sa mâchoire, on peut voir la tête d'un oiseau au bec crochu, dont l'œil est recouvert d'un motif tripartite. 


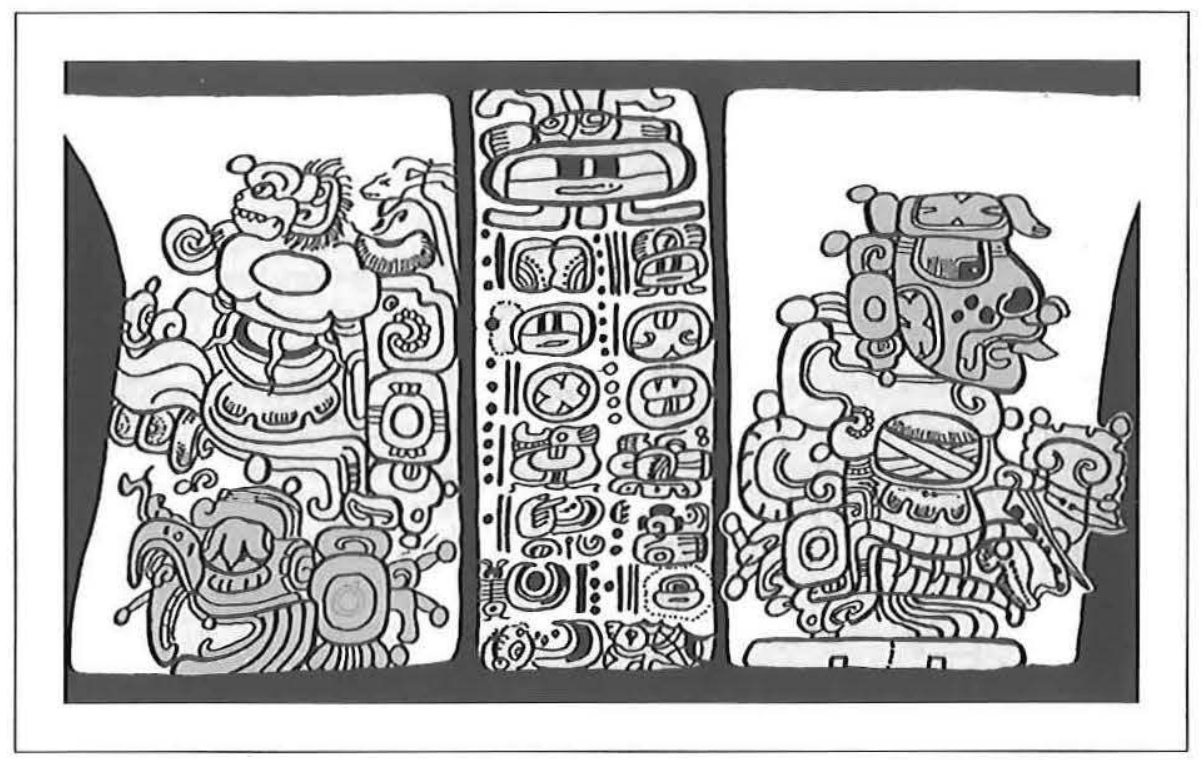

FIG. 8 - Le jour tombe

Río Azul, Tombe 1 .

Les deux monstres cauac sont terrestres, le jaguar représente le soleil nocturne et l'oiseau le soleil diurne. On peut donc interpréter l'image de droite comme celle du soleil qui s'apprête à s'enfoncer en terre, c'est-à-dire se coucher, pendant qu'à gauche, il s'apprête - sous la forme de l'oiseau - à sortir de terre, c'est-à-dire à se lever. Rien qui fasse ici référence à des rois. Il est cependant probable que cette double image illustre la succession dynastique, à cause du contexte des peintures qui décorent une tombe royale et de l'iconographie comparable des Monuments 23 et 24 de Quirigua.

\section{Monument 23 de Quirigua}

Pour sculpter les Monuments 23 et 24 de Quirigua, on a utilisé des rochers de grès peu épais dont on a conservé le contour originel irrégulier. Ces pierres ont servi d'autels aux Monuments 15 et 16 qui montrent l'émergence du roi hors du monstre terrestre bicéphale, et célèbrent donc son accession. Ces monuments, connus aussi comme Zoomorphes $\mathrm{O}$ et $\mathrm{P}$, sont datés respectivement 790 et 795 de notre ère. Leurs autels ont pour thème principal la descente du roi-soleil dans l'inframonde à deux moments successifs. 
Sur le Monument 23, le roi est placé horizontalement, mais non étendu, au-dessus de la terre, figurée conventionnellement par des $\mathrm{T}$ concentriques (Figure 9a). Sa posture désarticulée indique qu’il tombe du ciel, sur fond de nuages analogues à ceux du haut de la Stèle 1 de Jimball (Jones and Satterthwaite 1982, figure 78) ou à ceux du dessus de la porte intérieure du Temple 22 de Copán (Maudslay 1889-1902, I, plate 12). Il porte un masque, apparemment de jaguar, comme symbole du soleil nocturne. Trois bandes nouées (symbole sacrificiel) entourent son front, ses poignets et ses chevilles. Un whistongue, un emblème de sacrifice qui combine les favoris et la langue du jaguar, couronne son crâne et un autre orne ses joues et sa poitrine, comme sur la Stèle B de Copán (Baudez 1994, p. 26, figure $5 A$ ). Un serpent s'échappe de sa tête. Son corps est marqué de signes cauac. Il porte un petit bouclier sur le dos de la main gauche et tient dans la droite un masque à poignée.

Le roi mort, l'équivalent de la tête de jaguar de la peinture de Rio Azul, ne touche pas encore terre, mais en est tout près. Entre les textes glyphiques ${ }^{5}$, le premier T est empli de signes cauac, le second contient des coquillages vus en section. Les deux $\mathrm{T}$, au contenu différent, représentent deux étages ou deux aspects de l'inframonde dans lequel va s'enfoncer le roi. À l'autre bout de la sculpture, on identifie la tête d'un ara, symbole du soleil diurne, prêt à prendre la place du roi défunt dans le ciel, comme sur l'image de gauche de Rio Azul.

\section{LE CRÉPUSCULE : LE ROI S'ENFONCE EN TERRE}

\section{Monument 24, Quirigua}

Le roi, dont le visage est recouvert d'un masque de jaguar à demi décharné, s'enfonce par une large fente pratiquée dans le $\mathrm{T}$ terrestre, orné ici de signes cauac (Figure 9b). Le personnage est en mouvement, comme le montre le balancement du pagne. Il supporte un serpent bicéphale aux têtes squelettiques, dont la tête arrière est inversée. Deux serpents sortent de son crâne et de minces filets coulent de sa bouche.

Son successeur est représenté ici aussi comme un ara, mais de façon plus complète ; on reconnaît, de droite à gauche, la tête au bec crochu, l'aile dont l'armature est une tête de serpent et les pattes griffues. La différence de traitement des aras s'accorde bien à la position du roi-mort-jaguar. Sur le monument précédent, le roi défunt n'a pas encore touché terre, et seule pointe la tête de l'oiseau. Sur le Monument 24, le roi est déjà bien « enterré » et l'oiseau presque entièrement dégagé. La continuité de la séquence dynastique est ainsi démontrée. 

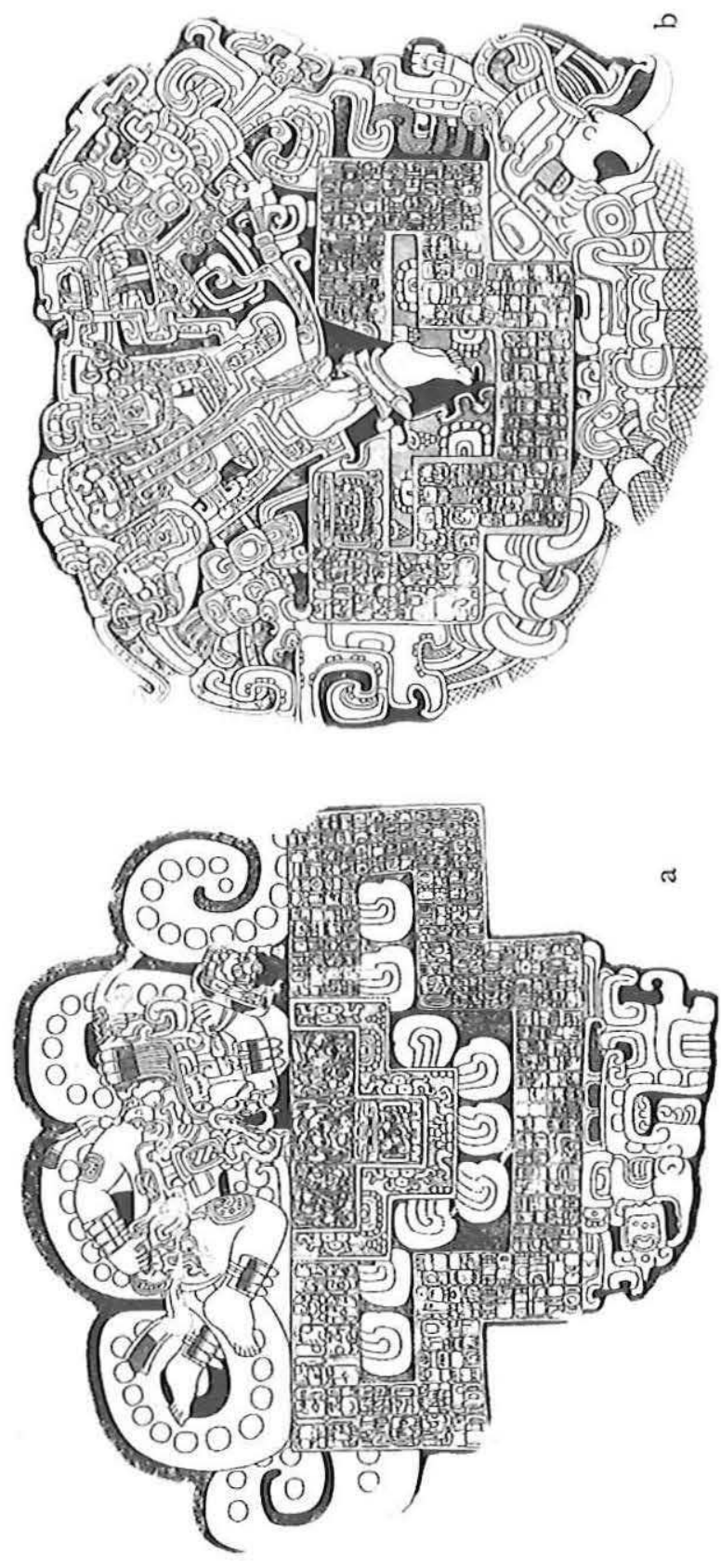

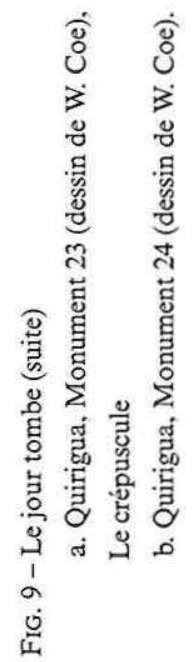




\section{LA NUIT}

\section{Couvercle du sarcophage, temple des Inscriptions, Palenque}

On peut y voir le roi dans les mâchoires décharnées du monstre terrestre (Figure 10a). Comme la tête et les mains du défunt se trouvent en dehors de la gueule, il est montré en mouvement par rapport au monstre. Ce mouvement est-il ascendant ou descendant ? Si le roi s'élève et sort des mâchoires, c'est une image de résurrection qui nous est présentée ; s'il descend et s'enfonce dans la gueule décharnée, c'est sa mort qui est illustrée. C'est cette dernière interprétation que nous favorisons. En effet, le roi tombe en arrière dans la même posture que les captifs saisis aux cheveux et promis au sacrifice des linteaux de Bonampak et de Yaxchilan. Ses mains et ses pieds vont en tous sens et son corps paraît désarticulé comme ceux des cadavres sacrifiés de Monte Alban, longtemps appelés « Danzantes ». Cette posture contraste avec l'attitude majestueuse des rois de Balamkú ou celle du maïs personnifié qui jaillit de la carapace fendue d'une tortue (Robicsek and Hales 1981, vessel 117, p. 91, figures 57 et 58). Elle est, en revanche, comparable à celle des rois défunts de Copán sur la Stèle $\mathrm{N}$, avalés par un crocodile marqué de signes cauac; leur chute est indiquée par une posture désordonnée qui contraste avec l'allure majestueuse de leurs successeurs (Figure 10b). Ils portent des bracelets et des ornements de cheville réservés aux ancêtres ; une coquille remplace leur oreille.

Le roi défunt de Palenque disparaît dans l'inframonde. Au bout de son nez, un os remplace la perle de jade qui symbolise le souffle vital des souverains vivants.

\section{Au bout de la NUIT}

\section{Stèle 11 de Copán}

La Stèle 11 (CPN 60) de Copán provient très probablement de la pièce du fond de la Structure 18, le temple funéraire du roi Soleil Levant (Figure 11). Elle montre le souverain dans l'inframonde, évoqué par des coquilles prolongées d'os - symboles de mort - qui encadrent ses jambes. Le roi ne descend plus ; ses pieds reposent sur la grande coquille qui représente le fond des enfers. Il est arrivé là au terme de son voyage dans le monde souterrain. À gauche de son visage, la hache fumante, un des attributs de la foudre personnifiée, est plantée dans son front. Sur la dalle qui ferme son sarcophage, le roi de Palenque exhibe le même attribut. On l'interprète fréquemment comme l'insigne d'un soi-disant dieu K'awil, " patron des gouvernants et de l'agriculture ", auquel le souverain chercherait à s'identifier. On trouve aussi la hache fumante plantée dans le front de trois des ennemis 

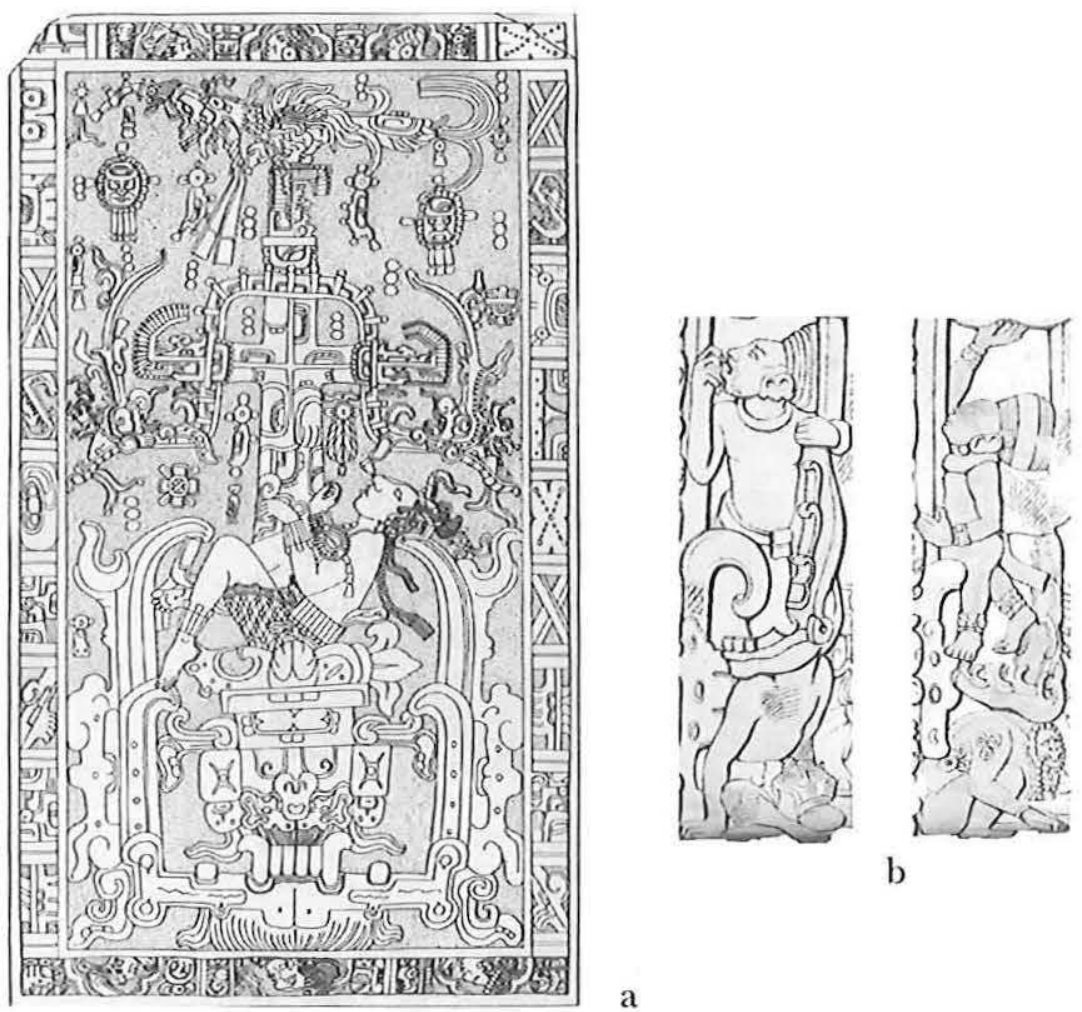

b

a

FIG. 10-La nuit

a. Palenque, temple des Inscriptions, couvercle du sarcophage (dessin de Merle Greene R.), b. Copán, Stèle N, détails.

étendus morts sur les marches de l'escalier hiéroglyphique de Copán (Gordon 1902, plates V, XII). L'association de ce motif à des morts peut donc signifier non que le personnage s'identifie à la foudre, mais plutôt qu'il est lui-même " foudroyé "), mort en quelque sorte.

\section{Conclusions}

Le cycle commencé avec la frise de Placeres, où le roi est sur le point de quitter le monde souterrain de la nuit, est bouclé avec la Stèle 11 de Copán. Parmi les 


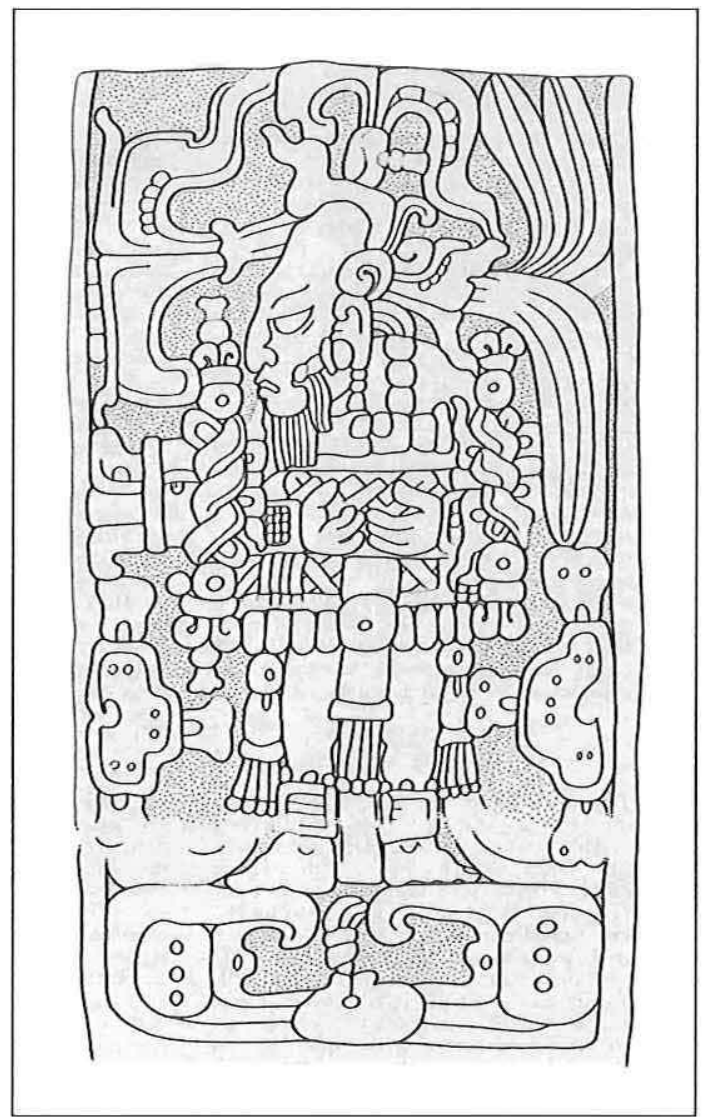

FIG. 11 - Au bout de la nuit Copán, Stèle 11 (dessin de B. Fash).

images qui illustrent les étapes du parcours solaire, certaines assimilent le roi au soleil en le situant par rapport à la terre et au ciel. D'autres, plus explicites, montrent ensemble le roi défunt et son successeur, insistant ainsi sur la continuité de la succession dynastique. Quand le jaguar se couche dans le monde souterrain, l'ara s'apprête à monter au ciel. Le roi est mort, vive le roi ! Comme le cycle solaire, la succession dynastique ne souffre aucune interruption. La métaphore solaire, de plus, associe directement la fertilité terrestre au souverain qui émerge de terre et fait du roi-soleil au zénith, le maître absolu de l'univers.

Le parcours cosmique qui illustre la carrière royale est matérialisé à Palenque par les trois temples du Groupe de la Croix, qui constituent les trois stations d'un 
même parcours rituel (Baudez 2002). Dans l'ordre donné par l'inscription ininterrompue d'un édifice à l'autre, le parcours commence avec le temple de la Croix qui, au nord et au niveau le plus élevé, représente le ciel ; la deuxième station est le temple du Soleil, à l'ouest et au niveau le plus bas, qui figure l'inframonde ; la dernière est le temple de la Croix Feuillue, à l'est et à un niveau intermédiaire qui est celui de la terre des hommes. Toujours à Palenque, mais cette fois dans le Palais, un microcosme a été construit pour y jouer la mort et la renaissance du roi précédant son couronnement (Baudez 1996b). Comme le soleil couchant, le jeune souverain s'enfonçait en terre par un escalier qui menait de la Maison K - à l'ouest - aux Souterrains ; le séjour qu'il passait dans l'inframonde correspondait à la nuit et à sa mort ; sa renaissance, analogue à un lever de soleil, s'effectuait par l'escalier qui débouchait dans la Maison E - à l'est - où avaient lieu les cérémonies du couronnement.

À Copán, la succession dynastique est parfois exprimée par des stèles à double face, comme les Stèles 5 et C (Baudez 1994) : le jeune souverain occupe alors l'un des grands côtés du monument, et, sur l'autre, on a représenté le feu roi sous les traits d'un vieillard barbu (Stèle C) ou porteur d'un masque de jaguar (Stèle 5).

À Placeres, le roi est soleil parce qu’il est déguisé en oiseau. Ả Balamkú, il est pleinement anthropomorphe et sa nature solaire ne nous est révélée que parce qu'un monstre terrestre le vomit. Sur le décor de Margarita, son nom (à moins que ce ne soit un titre ou un blason) remplace son effigie ; ce n'est sans doute pas par hasard si le fondateur de la dynastie a précisément choisi la combinaison des deux symboles du soleil diurne. Le successeur du roi défunt est un oiseau à Rio Azul et Quirigua. Sous forme humaine, le feu roi s'oppose au nouveau roi par son attitude disloquée provoquée par la chute ; il est masqué à Calakmul et Quirigua, ainsi qu'à Copán sur la Stèle 5. Sur le couvercle du sarcophage de Palenque et sur la Stèle 11 de Copán, il n'est pas masqué mais « foudroyé ». Si la hache fumante indique sans ambiguïté le roi défunt, le masque n'est peut-être alors plus nécessaire.

La terre d'où émerge le souverain et dans laquelle il s'enfonce peut prendre des aspects figuratifs, comme celui du monstre cauac, d'un animal amphibie (crapaud ou crocodile), ou de la résidence des bacabs. On a eu aussi recours à des formes purement conventionnelles comme les T concentriques des Monuments 23 et 24 de Quirigua ou la frise à contenu glyphique de Margarita (cauac et bandes croisées) et de Piedras Negras (caban). Si le monstre terrestre est un concept très ancien comme le montrent ses formes ancestrales dans l'art olmèque et dans celui d'Izapa, les T concentriques, dérivés du médaillon cruciforme, sont plus récents.

Au Préclassique récent et au Classique ancien, le ciel est montré comme une gueule frontale figurative ou conventionnelle (avec le motif comprenant des incisives taillées en T et deux crocs en crochet) souvent accompagnée sur les côtés par deux têtes verticales de serpent (Figures 3a, 4, 7). Le décor de Margarita comprend une des premières apparitions du monstre bicéphale formant voûte ; 
cette image du ciel est là doublée par la gueule conventionnelle. Au Classique ancien, la frise qui constitue le corps du monstre comporte plusieurs signes, le plus remarquable étant celui de l'étoile, T510. Au Classique récent, la frise céleste (sky band) devient un répertoire complexe de corps et de phénomènes célestes (lune, soleil, nuit, étoile) auxquels se mêlent des parties du monstre originel.

Avec son parcours de l'univers sous les traits du soleil, le roi maya a acquis une dimension cosmique dès les débuts de la période classique, en même temps que l'on assistait à l'érection de stèles à intervalles réguliers et que l'on inscrivait dans la pierre l'histoire des règnes. Les images fortes, illustrant ce parcours, ont certainement contribué à légitimer de façon incontestable la monarchie maya dès ses débuts. *

* Manuscrit reçu en janvier 2005, accepté pour publication en janvier 2006.

\section{Notes}

1. L'emblème tripartite avec les bandes croisées fait partie de l'iconographie du Classique ancien, en particulier sur les Stèles 2 et 6 de Tikal (Jones and Satterthwaite 1982, figures 2, 9) et sur les boîtes en céramique pour dépôts cérémoniels (Hellmuth 1987, figures 70-72).

2. Ainsi sur le vase cylindrique à couvercle provenant de l'Acropole centrale de Tikal et daté du Classique ancien (Kubler 1969, figure 53) et sur la banquette de la Structure 9 N-82 de Copán du Classique récent (Webster 1989, figure 13).

3. Voir Quirarte 1973, figure 3.

4. Des motifs comparables figurent sur des vases Tzakol (Hellmuth 1987, figures 281, 282).

5. Les textes des deux monuments mettent l'accent sur la date d'accession (9.17.14.16.18 9 Etzn'ab 1 Kankin, soit le 11 octobre 785) du roi Sky Xul. Sur le Monument 23, des nombres de distance permettent de se référer à près d'une vingtaine de dates différentes, parmi lesquelles figure celle de la victoire du roi Cauac Sky sur Copán le 29 avril 738 (9.15.6.14.6 6 Cimi 4 Tzec). Sur le Monument 24, diverses dates se réfèrent à des événements (non précisés) survenus avant l'accession de Sky Xul. Un nombre de distance de 9.18.5.0.0 nous renvoie 3965 années en arrière, au point de départ de la dernière création (ou Grand Cycle), datée 13.0.0.0.0, et qui correspond à 3114 avant notre ère (Jones 1983).

\section{RÉFÉRENCES BIBLIOGRAPHIQUES}

BAUDEz Claude-François

1988 "Solar cycle and dynastic succession in the Southeast Maya zone ", in Elizabeth H. Boone et Gordon R. Willey (éd.), The Southeast classic Maya zone, Dumbarton Oaks Trustees For Harvard University, Washington, DC, pp. 125-148.

1994 Maya sculpture of Copán : the iconography, University of Oklahoma Press, Norman/Londres.

1996a «La casa de los cuatro reyes de Balamkú », Arqueología mexicana, III (18), pp. 36-41, Mexico. 
1996b "Arquitectura y escenografía en Palenque : un ritual de entronización », Res, 29/30, pp. 172-179, Cambridge, Mass.

2002 Une histoire de la religion des Mayas, Albin Michel, Paris.

Buikstra Jane E., T. Douglas Price, Lori E. Wright et James A. Burton

2004 "Tombs from the Copan acropolis : a life-history approach », in Ellen E. Bell, Marcello A. Canuto et Robert J. Sharer (éd.), Understanding Early, Classic Copan, University of Pennsylvania, University Museum of Archaeology and Ethnology, Philadelphia, pp. 191-212.

FASH William L.

1991 Scribes, warriors and kings. The city of Copán and the ancient Maya, Thames and Hudson, Londres.

FReIDEL David

2000 "Mystery of the Maya facade. Astute detective work gives new meaning to a looted artwork », Archaeology, 53, pp. 5, 24-28, The Archaeological Institute of America, Washington DC.

Gordon George Byron

1902 The hieroglyphic stairway, ruins of Copan. Report on explorations by the museum, Harvard University, Memoirs of the Peabody Museum of American Archaeology and Ethnology 1 (6), Cambridge, Mass.

GraHAM Ian

1967 Archaeological explorations in el Peten, Guatemala, Tulane University, Middle American research institute, publication 33, New Orleans.

1979 Corpus of Maya hieroglyphic inscriptions, Harvard University, Memoirs of the Peabody Museum of Archaeology and Ethnology 3 (2), Cambridge, Mass.

GreEne Robertson Merle

1983 The sculpture of Palenque. I. The temple of the inscriptions, Princeton University Press, Princeton.

1991 The sculpture of Palenque. IV. The cross group, the north group, the Olvidado, and other pieces, Princeton University Press, Princeton.

Hellmuth Nicholas M.

1987 Monster und Menschen in der Maya-Kunst. Eine Ikonographie der alten Religionen Mexikos und Guatemalas, Akademische druck-u. Verlagsanstalt. Graz., Graz.

JoNES Christopher

1983 "New drawings of Monuments 23 and 24, Quirigua, Guatemala », in Robert J. Sharer, Edward M. Schortman et Patricia A. Urban (éd.), Quirigua reports, vol. II, paper 15, pp. 137-140, University of Pennsylvania, University Museum monograph 49, Philadelphia.

JONES Christopher et Linton SATterthwaIte JR

1982 The monuments and inscriptions of Tikal: the carved monuments, Tikal reports 33a, University of Pennsylvania, University Museum monographs 44, Philadelphia. 
KuBLer George

1969 Studies in Classic Maya iconography, Connecticut Academy of Arts and Sciences, Memoirs of the Connecticut Academy of Arts and Sciences 18, New Haven.

1977 Aspects of Classic Maya rulership on two inscribed vessels, Dumbarton Oaks research library and collection, Studies in pre-columbian art and archaeo$\operatorname{logy} 18$, Washington, DC.

Lizana Bernardo

1893 Historia de Yucatán. Devocionario de nuestra señora de Izamal y conquista espiritual, Museo nacional de México, Mexico.

Marcus Joyce et Kent V. Flannery

1996 Zapotec civilization. How urban society evolved in Mexico's Oaxaca valley, Thames and Hudson, Londres.

Maudslay Alfred Percival

1889-1902 "Archaeology », Biologia Centrali-Americana, 4 vols, Londres.

PARSONS Lee Allen

1986 The origins of Maya art: momumental stone sculpture of Kaminaljuyu, Guatemala, and the southern Pacific coast, Dumbarton Oaks research library and collection, Studies in pre-columbian art and archaeology 28 , Washington DC.

QUIRARTE Jacinto

1973 Izapan-style art. A study of its form and meaning, Dumbarton Oaks research library and collection, Studies in pre-columbian art and archaeology 10, Washington DC.

Reents-Budet Dorie, Ellen E. Bell, Loa P. Traxler et Ronald L. Bishop

2004 "Early Classic ceramic offerings at Copan : a comparison of the Hunal, Margarita, and Sub-Jaguar tombs ", in Ellen E. Bell, Marcello A. Canuto et Robert J. Sharer (éd.), Understanding Early Classic Copan, University of Pennsylvania, University Museum of Archaeology and Ethnology, Philadelphia, pp. 159-190.

Robicsek Francis et Donald M. Hales

1981 The Maya book of the dead. The ceramic codex, The University of Virginia Art Museum, Charlottesville, Virginia.

Schele Linda et Mary Ellen Miller

1986 The blood of kings. Dynasty and ritual in Maya art, Kimbell art museum, New York/Fort Worth.

Stuart David

2004 "The beginnings of the Copan dynasty : a review of the hieroglyphic and historical evidence ", in Ellen E. Bell, Marcello A. Canuto et Robert J. Sharer (éd.), Understanding Early Classic Copan, University of Pennsylvania, University Museum of Archaeology and Ethnology, Philadelphia, pp. 215-247. 


\section{THOMPSON John Eric}

1970 Maya history and religion, University of Oklahoma Press, Norman.

1971 Maya hieroglyphic writing : an introduction, University of Oklahoma Press, Norman.

\section{Webster David (éd.)}

1989 The house of the bacabs, Copan, Honduras, Dumbarton Oaks research library and collection, Studies in pre-columbian art and archaeology 29, Washington DC. 